\title{
Editorial
}

\section{Antropología en el contexto gubernamental}

\author{
Anthropology in the governmental context \\ iD Daniel Velandia Díaz¹; iD Claudia Cáceres Domínguez²
}

En el XVI Congreso de Antropología en Colombia y V Congreso de la Asociación Latinoamericana de Antropología realizados en 2017 en la ciudad de Bogotá, llevamos a cabo, junto con un nutrido grupo de ponentes y asistentes y, con nuestros colegas José Francisco Hurtado Gamboa y Claudia Alexandra Duque Fonseca, el simposio: "Antropología en el contexto gubernamental: incidencia política de la disciplina desde el poder ejecutivo". Desde entonces, convencidos de la necesidad de compartir, analizar y divulgar algunas características, experiencias e historias del ejercicio profesional de la antropología en el contexto de los gobiernos, presentamos este dossier.

La presencia de la antropología en los escenarios de toma de decisión en el terreno político no es nueva. Sabemos que, desde la antropología de las expediciones, denominación que Peacock (2002) da al periodo de la formación de la disciplina a finales del siglo XIX, algunas acciones de la antropología han tenido un vínculo con los gobiernos y han incidido en la relación entre las élites locales o ultramarinas y diversos grupos sociales. Una referencia indispensable en el contexto latinoamericano es la utilización de la etnografía con la finalidad de inspeccionar las condiciones laborales en Argentina, justamente a comienzos del siglo XX (Brunatti, Colángelo y Soprano, 2002). No obstante, a muchas antropólogas y antropólogos nos parece necesario hacer una revisión detenida de la historia reciente, justamente, cuando por los avatares de la institucionalización de la disciplina, parece que hay muchos (des)acuerdos tácitos sobre el quehacer en relación con lo político.

En Colombia, particularmente, se ha presentado un cambio trascendente después de la Constitución de 1991. En ese mismo año, la ratificación del Convenio 169 de la Organización Internacional del Trabajo (OIT), mediante la promulgación de la Ley 21, dio paso a nuevas relaciones sociopolíticas en lo concerniente con la nación y la diversidad cultural y étnica. Por supuesto, estos son apenas unos hitos de las transformaciones sociales y jurídicas en el país, pero son indicativos de un momento relevante de cambio social. En un terreno menos visible, antropólogas y antropólogos se fueron acomodando a esta configuración política y se generó, o por lo menos eso podemos suponer, una profesionalización simultánea con la implementación de la constitución (Jimeno, 2005).

\footnotetext{
${ }^{1}$ Doctor en Antropología. Profesor Universidad del Magdalena. ORCID ID: 0000-0001-5523-8479. Correos electrónicos: dvelandia@unimagdalena.edu.co

${ }^{2}$ Antropóloga. ORCID ID: 0000-0001-6556-4796. Correos electrónicos: claudia.caceres.dominguez@usal.es
} 
Estamos convencidos que es necesario conocer con mayor profundidad los cambios que vivieron las generaciones de antropólogas y antropólogos que trabajaron en los noventa con los gobiernos. De la misma forma, nos parece importante reflexionar con las generaciones actuales acerca del proceso de profesionalización como especialistas en la diversidad étnica y cultural, si se nos permite esta expresión ciertamente restringida. Este título no es gratuito, a pesar de las enormes diferencias conceptuales y de opinión que pudiesen existir al interior de nuestro gremio, es difícil oponerse a los imaginarios que la sociedad en su conjunto tiene sobre nosotros. Dentro de las formas estereotipadas que hemos recibido como apodo $\mathrm{y}$, que parecen seguir en uso a pesar de nuestra incomodidad, están las de tiestólogos e indiólogos, además de la de los mechudos como lo presenta Valentina Pellegrino en "Patinar una carpeta: el grupo de trabajo del Auto 004 en la Dirección de Asuntos Indígenas". Sin lugar a dudas, además de ser peyorativas, reflejan una realidad negativa para nosotros puesto que se nos encasilla en un lugar de trabajo y, muchas veces, con intenciones instrumentales por parte de sectores económicos o políticos interesados.

$\mathrm{Si}$, de una parte, no se reconoce suficientemente la actividad de investigación de la antropología, lo que, valga decir, equivale a desconocer que nuestros aportes no se pueden definir de antemano. De otra parte, no se hace explícito el campo complejo de acción al que se enfrentan los profesionales en antropología y, en otras ciencias sociales, cuando deciden o tienen la oportunidad laboral de trabajar en los gobiernos. Entonces, para entender este campo complejo es necesario hacer etnografías del Estado y de las burocracias, pero adicionalmente y quizás de mayor importancia, es necesario reconocer los aprendizajes de nuestra historia profesional. Por tanto, consideramos que es imprescindible conocer el legado que dejan estas experiencias para las siguientes generaciones de antropólogas y antropólogos. Ojalá pudiéramos valorar el trabajo de muchas personas que han hecho aportes silenciosos para la sociedad en su conjunto desde nuestra disciplina.

Lejos de ser un listado exhaustivo, encontramos los siguientes asuntos notorios de las experiencias de antropólogas y antropólogos en los gobiernos:

1. Hay una dualidad en las dinámicas gubernamentales, que por una parte requieren el conocimiento antropológico $\mathrm{y}$, por otra, lo instrumentalizan.

2. Cada profesional desarrolla redes de trabajo que le permiten salir adelante con sus procesos de trabajo, además, los funcionarios cuidan celosamente sus relaciones con diferentes comunidades, organizaciones de la sociedad civil y líderes.

3. En muchas actividades, la solicitud hacia antropólogas y antropólogos es la emisión de un "concepto"; la importancia de los conceptos radica en que son determinantes para la toma de decisiones en diferentes instancias de los gobiernos y tienen una incidencia política y pública notoria.

4. Trabajar en los gobiernos parece haber generado una fisura al interior de la antropología, de forma simplista, se puede reducir a la existencia de una antropología que se ha dedicado a la investigación y a la docencia $y$, otra, una antropología que algunos llaman aplicada, práctica o de la acción.

5. Nuestra disciplina es diversa, esto se manifiesta en los diversos lenguajes que utilizamos en relación con los lugares de trabajo y la posición que se ocupa dentro de las administraciones. 
6. Para facilitar el trabajo, antropólogas y antropólogos requieren la articulación entre los gobiernos (nacional, departamental y municipal) y los institutos, las escuelas y las líneas de investigación en antropología.

7. Es imprescindible poner en la agenda pública la necesidad de abogar por nuestros derechos laborales; en Colombia se ha naturalizado la existencia y renovación de contratos de prestación de servicios, pero estamos convencidos que no es una práctica adecuada para la profesión.

8. Los procesos sociopolíticos que antropólogas y antropólogos conocen y desarrollan al cabo del tiempo pueden detenerse, particularmente, porque quienes toman decisiones políticas y/o administrativas tienen la atribución de medir la postura política o los intereses y, en consecuencia, juzgar la pertinencia de la continuidad de las personas en sus empleos.

9. Podemos decir que estas circunstancias, si bien tienen diferentes efectos en el ejercicio de la profesión, en alguna medida vulneran el valor y la autoridad de la antropología como disciplina, campo y comunidad de conocimiento.

Finalmente, invitamos a lectoras y lectores a revisar el artículo de Marcela Valdata: La inserción del Antropólogo en la Dirección de Pueblos Originarios, Municipalidad de Rosario, Santa Fe, Argentina: relaciones de fusión y fisión, es nuestro punto de partida para comprender las relaciones actuales entre el gobierno y los grupos étnicos en Argentina. A continuación, el artículo de Valentina Pellegrino: Patinar una carpeta: el grupo de trabajo del Auto 004 en la Dirección de Asuntos Indígenas, hace énfasis en las actividades de un grupo de antropólogos para dar cumplimiento a una orden judicial crucial en la historia reciente del país. Posteriormente, el artículo de Daniel Velandia Díaz: Trabajadores Enfermos: Investigación social compartida y exigencia de Derechos Humanos, que muestra un proceso de investigación entre antropólogos y abogados en el contexto de un convenio interinstitucional vinculado al Ministerio de Trabajo de Colombia. Para cerrar, el artículo de Janeth Silvia Salazar Patiño y José Luis Arriaga Ornelas: Evaluaciones de impacto social. Los antropólogos en la elaboración de proyectos de la Comisión Federal de Electricidad en México, donde se presentan detalladamente las diferentes actividades y problemáticas que enfrentan antropólogos sociales en calidad de especialistas cuando hacen análisis de impacto social. La actualidad de los artículos que presentamos (segunda década del siglo XXI) es una invitación a reflexionar sobre nuestro quehacer con el propósito de buscar líneas de acción que nos permitan un mayor reconocimiento y unión como sujetos sociales y políticos.

\section{Referencias}

Brunatti, O.; Colángelo, M. A. y Soprano, G. (2002). "Observar para legislar. Métodos etnográficos e inspección del trabajo en la Argentina a principios del s. XX”. En Visacovsky y Guber (Comp.), Historia y estilos de trabajo de campo en Argentina (pp. 79-126). Buenos Aires: Antropofagia.

Jimeno, Myriam. (2005). La vocación crítica de la antropología en Latinoamérica. Antípoda (1). pp. 43-65.

Peacock, James. (2002). Action comparison: Efforts towards a global and comparative yet local and active anthropology. En Gingrich and Fox (Ed.), Anthropology by Comparison (pp. 4469). New York: Routledge. 